\title{
Médiévales
}

Langues, Textes, Histoire

47 | automne 2004

Îles du Moyen Âge

\section{Michelle Bubenicek, Quand les femmes gouvernent. Droit et politique au XIV siècle: Yolande de Flandre, préface de Michel Parisse}

Paris, École des chartes, 2002 (Mémoires et documents de l'École des chartes, 64), 443 p., 14 fig., index.

\section{Anne-Hélène Allirot}

\section{(2) OpenEdition}

Journals

Édition électronique

URL : https://journals.openedition.org/medievales/1082

DOI : 10.4000/medievales. 1082

ISSN : $1777-5892$

Éditeur

Presses universitaires de Vincennes

Édition imprimée

Date de publication : 1 décembre 2004

Pagination : 175-177

ISBN : 2-84292-157-7

ISSN : 0751-2708

Référence électronique

Anne-Hélène Allirot, « Michelle Bubenicek, Quand les femmes gouvernent. Droit et politique au xIv siècle Yolande de Flandre, préface de Michel Parisse », Médiévales [En ligne], 47 | automne 2004, mis en ligne le 13 mars 2006, consulté le 22 avril 2022. URL : http://journals.openedition.org/medievales/1082 ; DOI : https://doi.org/10.4000/medievales. 1082

Ce document a été généré automatiquement le 22 avril 2022.

Tous droits réservés 


\section{Michelle Bubenicek, Quand les} femmes gouvernent. Droit et politique au XIV siècle: Yolande de Flandre, préface de Michel Parisse

Paris, École des chartes, 2002 (Mémoires et documents de l'École des chartes, 64), 443 p., 14 fig., index.

\section{Anne-Hélène Allirot}

1 Cet ouvrage est la version réduite de la thèse de doctorat nouveau régime soutenue en 1998 par Michelle Bubenicek, en prolongement d'une thèse de l'École nationale des chartes. L'auteur retrace le parcours politique de Yolande de Flandre, successivement réputée «virago, mère possessive, fausse-monnayeuse, presbytéricide et coupable de lèse-majesté ». Fille de Robert de Cassel et de Jeanne de Bretagne, née le 15 septembre 1326, Yolande est l'héritière du très convoité apanage de Cassel. Épouse d'Henri IV de Bar, elle devient veuve en 1344. Elle se remarie avec Philippe de Navarre en 1353, second époux dont elle s'éloigne nettement à partir de 1356. Veuve à nouveau en 1363 , Yolande meurt à son tour en 1395. Sa vie mouvementée est jalonnée par les différents combats qu'elle dut mener pour tenter de conserver un patrimoine qui lui échappe progressivement, jusqu'à se trouver littéralement « dépouillée » de sa fortune et de ses droits. Il ne s'agit pas d'établir une simple biographie de cette noble dame, mais plutôt d'apporter une contribution à l'histoire de la politique, du droit, et de la société nobiliaire du xive siècle à travers le récit de " l'ambition légitime d'une princesse face à des hommes de pouvoir ». Pour cela, l'auteur a mené un travail d'analyse considérable et extrêmement minutieux des abondantes archives qui concernent Yolande. Les trois grands types de sources convoquées sont les lettres et actes, les comptes, et les pièces de procès. Elles sont réparties dans trois fonds principaux : le fonds lorrain, le fonds parisien, et celui du Nord. L'auteur décrit très précisément ces sources et présente les outils aidant à leur dépouillement. 
2 L'étude débute par une présentation méthodique de l'ascendance de Yolande, de son patrimoine familial et de son premier mariage, puis s'organise en deux grandes parties chronologiques et thématiques. La première traite du pouvoir exercé par Yolande de Flandre dans le cadre familial et conjugal et en particulier lors de son premier veuvage. Son installation en tant que régente du Barrois ne va pas de soi. Comme c'est souvent le cas, le testament de son époux, le comte de Bar, aurait plutôt tendance à écarter la veuve d'une possible régence. Yolande de Flandre tient pourtant le gouvernement du comté durant quinze ans, le temps pour son fils aîné, qui meurt rapidement, puis pour son second fils, d'atteindre l'âge de l'émancipation. Michelle Bubenicek porte une attention particulière à la terminologie de cette régence et à l'évolution du personnel autour de Yolande. La jeune veuve se heurte à de vives oppositions, notamment de la part de ses cousins au nom de leur proximité de lignage. Pour eux, le comté devrait leur revenir en "droite ligne». L'auteur retrace une histoire politique complexe faite de complots, luttes d'influence, actes de fidélité et de trahison, et rythmée de réconciliations orchestrées par le roi Philippe VI de Valois. Une spécificité du pouvoir au féminin transparaît au fils de ces étapes : une femme est une victime désignée dans les luttes patrimoniales, même si la princesse en question semble présenter de grandes qualités de gouvernant.

3 Par son remariage avec Philippe de Navarre, Yolande de Flandre renoue avec le statut classique des femmes mariées. L'étude de la gestion de ses biens propres et de la sigillographie montre une dame juridiquement soumise à son époux. Michelle Bubenicek remarque toutefois une modification de cet état de fait à partir de 1356 : l'abandon du titre de comtesse de Longueville signale qu'une mésentente est survenue entre les deux époux. Cette mésentente de nature politique entraîne une séparation de corps jusqu'au décès de Philippe. Yolande est d'ailleurs la dernière informée des funérailles de son conjoint!

4 Veuve pour la seconde fois en 1363, Yolande devient une actrice à part entière de la scène politique. Commence alors un combat pour ses droits et son patrimoine, que présente Michelle Bubenicek dans sa seconde partie, sans conteste la plus riche de l'étude. Yolande se bat d'abord pour obtenir la succession de Navarre et le douaire de Longueville face à la famille des Évreux-Navarre. Elle doit accepter d'avoir à racheter une partie de la communauté de biens. Le douaire de Longueville est l'objet d'un procès contre la partie Du Guesclin, soutenue par le roi Charles V, de 1367 à 1385.

5 Michelle Bubenicek s'attarde avec raison sur l'emprisonnement de Yolande au Temple en 1370, une peine qu'elle reçoit officiellement pour avoir arrêté le sire de Pierrefort. Cet épisode, rendu fameux du fait de l'engouement suscité au xix siècle par la « légende noire » de Yolande, s'inscrit dans la continuité des problèmes territoriaux de la princesse. Ce qui pourrait n'être qu'une anecdote savoureuse devient un exemple passionnant d'utilisation par le roi de la notion de lèse-majesté, alors en pleine construction théorique ${ }^{1}$, et de son droit de grâce pour régler à son profit une affaire de patrimoine. Yolande subit deux ans et demi d'emprisonnement et se voit dessaisie de son douaire du Clermontois, sanction de sa désobéissance. L'application de cette peine ne s'explique que dans le contexte des problèmes financiers de la royauté en temps de guerre. Le roi cherche alors à réduire ou contrôler les principaux douaires, comme Blanche de Navarre en fait par exemple l'expérience. Cette affaire soulève également un point intéressant du droit de succession. L'auteur note un fait curieux: le fils de Yolande, Robert de Bar, soutient l'arrestation de sa mère. Il lui doit des sommes 
considérables, suite à une rançon qu'elle a versée pour lui. Or le droit de Flandre permet à Yolande de confisquer une partie de l'héritage de son fils, notamment le très stratégique apanage de Cassel, enclave entre Flandre, Artois et Hainaut, que le roi redoute de voir passer à l'Empire. En 1373, Yolande doit capituler devant l'acharnement royal et donner immédiatement son patrimoine à son fils. Elle en garde cependant l'usufruit. L'arrestation de Yolande représente tout simplement la sanction d'une dame trop puissante face à la construction de l'État royal en cette fin du XIV siècle.

6 Cet apanage de Cassel est enfin, de 1388 à 1395, l'objet d'une offensive en règle de Philippe le Hardi. Michelle Bubenicek analyse avec une grande finesse les multiples procédures employées par le duc de Bourgogne pour le réduire progressivement à peau de chagrin: empiètements territoriaux, violations des droits de justice de Yolande, procédure en Parlement qui fait de Philippe le véritable maitre de l'apanage. On découvre un duc de Bourgogne utilisant à son profit les méthodes royales, en particulier la clause de "souveraineté et ressort », pour régler le sort de cette enclave au sein de sa principauté. L'auteur verse une contribution non négligeable à l'histoire de l'institution-apanage dans la construction de l'État en démontrant que l'apanage, à la fin du XIv ${ }^{e}$ siècle, repose uniquement sur le maintien de bonnes relations entre l'apanagé et l'autorité souveraine dont il dépend.

7 Cette étude témoigne d'une brillante maîtrise des archives administratives et judiciaires, exploitées jusque dans les nuances du droit médiéval. On pourrait reprocher à l'auteur, bien qu'ayant signalé le caractère très "impersonnel » de ces sources qui reflètent avant tout le fonctionnement d'une administration, de tendre à expliciter les faits par des jugements psychologiques concernant l'audace ou le tempérament de Yolande de Flandre, traits de caractère au sujet desquels aucune certitude ne peut être établie. Mais l'ensemble ne peut que combler le lecteur par la finesse d'analyses replacées dans une vaste problématique d'histoire des femmes au pouvoir. Cette recherche, axée sur les relations entre pouvoir et parenté, rend compte très exactement du statut d'une femme qui gouverne à la fin du Moyen Âge, et de l'importance prise par sa dotation patrimoniale dans l'exercice de son pouvoir. Le cheminement de Yolande est mis en perspective avec d'autres exemples de femmes de pouvoir des $\mathrm{XIV}^{\mathrm{e}}$ et $\mathrm{XV}^{\mathrm{e}}$ siècles : la princesse a subi conjointement tous les tourments qu'ont pu rencontrer Marguerite de Provence, Mahaut d'Artois ou Jeanne de Chalon en leur temps. Son parcours illustre en définitive la violence politique que peuvent éprouver ceux et surtout celles qui se heurtent à la construction de l'État naissant.

\section{NOTES}

1. Cf. C. Gauvard, «L'image du roi justicier en France à la fin du Moyen Âge d'après les lettres de rémission ", dans La Faute, la répression et le pardon. Actes du $107^{\circ}$ Congrès national des sociétés savantes, Brest, 1982, t. 1, Paris, 1984, p. 165-192. 